\title{
THE LANCET
}

\section{Interleukin-8 and development of adult respiratory distress syndrome in at-risk patient groups}

\author{
SEAMAS C. DONNELly ROBERT M. STRIETER STEVEN L. KUNKEL \\ ALFRED WALZ COLIN R. ROBERTSON DAVID C. CARTER \\ IAN S. GRANT ANTONY J. POLLOK CHRISTOPHER HASLETT
}

Neutrophils have been implicated in the pathogenesis of the adult respiratory distress syndrome (ARDS). We have measured concentrations of the neutrophil attractant interleukin- 8 in blood and bronchoalveolar lavage fluid (BAL) from patients at risk of ARDS.

We studied 29 patients from three groups at risk of developing ARDS: multiple trauma $(n=16)$, perforated bowel $(n=6)$, and pancreatitis $(n=7)$. ARDS developed in 7 of these patients. Interleukin-8 in BAL and blood samples taken on initial hospital presentation was measured by a sandwich enzymelinked immunosorbent assay. The mean BAL interleukin- 8 concentration was significantly higher for the patients who subsequently progressed to ARDS than for the non-ARDS group (3.06 [SE $2.64]$ vs $0.053[0.010] \mathrm{ng} / \mathrm{mL}, \mathrm{p}=0.0006)$. There was no difference between the groups in plasma interleukin-8 $(6.23[2.60]$ vs $5.12[2 \cdot 22] \mathrm{ng} / \mathrm{mL}$, $p=0.31)$. Immunocytochemistry suggested that the alveolar macrophage is an important source of interleukin-8 at this early stage in ARDS development.

This study provides evidence of a relation between the presence of interleukin- 8 in early BAL samples and the development of ARDS. The early appearance of interleukin-8 in BAL of patients at risk of ARDS may be an important prognostic indicator for the development of the disorder and reinforces the likely importance of neutrophils and the effects of their accumulation and activation in the pathogenesis of many cases of ARDS.

\section{Introduction}

Adult respiratory distress syndrome (ARDS) characteristically develops after a latent period of hours or days since the initiating or provoking insult. The progressive respiratory failure is associated with pathological features caused by the breakdown of alveolar capillary integrity within the lung and leakage of proteinrich fluid into the alveolar space. Despite improvements in intensive care support for patients with ARDS, mortality has remained at $50-90 \% .^{1}$ Research has tended to concentrate on patients with established ARDS in an intensive care setting. However, the disease process is likely to have been under way for hours or days before clinical presentation. The risk of progression to ARDS varies from $1 \%$ to $35 \%$, depending on the initiating or provoking insult. $^{2}$ At present it is not possible to identify clearly individuals or subgroups of patients who are at very high risk of this disorder.

It is generally believed that ARDS arises as a result of tissue injury secondary to inflammatory-cell sequestration, emigration, activation, and secretion of their histotoxic products. Neutrophils have received much attention as a key part of this process. ${ }^{3}$ Although ARDS has been described in

ADDRESSES: Respiratory Medicine Unit, University of Edinburgh, City Hospital, Edinburgh, UK (S. C. Donnelly, MRCPI, Prof C. Haslett, FRCP): Department of Pathology and Medicine, Division of Pulmonary and Critical Care Medicine, University of Michigan, Ann Arbor, USA (R. M. Strieter, MD, S. L. Kunkel, PhD); Theodor Kocher Institute, University of Berne, Switzerland (A. Walz, PhD); Departments of Accident and Emergency Medicine (C. R. Robertson, FRCPE), Surgery (Prof D. C. Carter, FRCSE), and Anaesthetics (A. J. Pollok, FFA RCS), Royal Infirmary, Edinburgh; and Intensive Therapy Unit, Western General Hospital, Edinburgh (I. S. Grant, FFA RCS). Correspondence to Prof Christopher Haslett, Respiratory Medicine Unit, University of Edinburgh, City Hospital, Edinburgh EH10 5SB UK. 
patients with peripheral-blood neutropenia, there is evidence implicating neutrophils specifically in most cases of ARDS. Histology of lung samples from ARDS patients shows an intense inflammatory infiltrate within the interstitium, which is predominantly neutrophilic. ${ }^{4}$ Dynamic studies in vivo with radiolabelling techniques showed increased localisation of neutrophils within the lung in active ARDS. ${ }^{5}$ Analysis of bronchoalveolar lavage fluid (BAL) samples from ARDS patients showed the presence of increased numbers of neutrophils ${ }^{6}$ as well as high concentrations of elastase ${ }^{7}$ and collagenase. ${ }^{8}$ Furthermore, ARDS patients' BAL has enhanced neutrophil chemotactic activity, and high concentrations of the neutrophil chemotactic factor interleukin- 8 have been reported. ${ }^{9}$

If neutrophils accumulate in the lungs early in the development of ARDS, specific neutrophil chemotactic signals should be detectable in vivo before lung injury is evident clinically. Leukotriene B4 and C5a have neutrophil chemotactic and activating properties in vitro, but the role of leukotriene B4 in ARDS is uncertain, ${ }^{10}$ and the lungs (and pulmonary macrophages in particular) seem to produce little $\mathrm{C} 5 \mathrm{a}$ in experimental models of lung inflammation. ${ }^{11}$ Among the family of cytokines whose primary functions include neutrophil activation and chemotaxis, interleukin-8 is an important member; within the lungs it is principally produced by macrophages. ${ }^{12}$ Although other cells may make substantial contributions, alveolar macrophages can express interleukin-8 mRNA within $60 \mathrm{~min}$ of stimulation with lipopolysaccharide tumour necrosis factor, or interleukin-1. ${ }^{13}$ These observations and the finding that BAL from patients with ARDS shows biochemical characteristics of this cytokine family suggest that interleukin -8 is a candidate for the initiation and progression of neutrophil-mediated events in ARDS. Circulating plasma concentrations of mediators likely to be important in the pathogenesis of ARDS (eg, C5a, endotoxin, tumour necrosis factor) have not proved useful as predictors of ARDS in at-risk patients. ${ }^{14,15}$ We therefore included measurement of interleukin-8 in $\mathrm{BAL}$ as well as in plasma.

\section{Patients and methods}

Patients presenting with three well-defined disorders predisposing to ARDS were eligible. We studied 7 patients with severe pancreatitis, who satisfied two or more of the established prognostic criteria for pancreatitis; ${ }^{16}$ samples from these patients were obtained on day 1 of hospital admission. 16 patients with severe multiple trauma, who required intubation in the accident and emergency department, were also eligible for study enrolment. The injury severity in this group was assessed by anatomical (injury severity score) and physiological (revised trauma score) methods. ${ }^{17}$ We also enrolled 6 patients with a clinical diagnosis of perforated bowel, for whom surgical intervention was planned; the lung lavage and blood sampling were done preoperatively when the patients were under general anaesthesia. Consecutive at-risk patients were enrolled at the Royal Infirmary and the Western General Hospital, Edinburgh. Patients with perforated bowel or pancreatitis gave informed consent themselves; for those with multiple trauma consent was obtained from relatives or guardians. In 7 further cases consent for bronchoscopy was refused ( 2 of these patients subsequently developed ARDS). The study was approved by the Lothian Health Board Ethics Committee.

ARDS was defined by a lung injury score of more than $2 \cdot 5 .^{18} \mathrm{This}$ value was obtained by scoring, on a scale of $0-4$, the extent of chest radiograph infiltrates, pulmonary compliance, ratio of arterial

\begin{tabular}{|c|c|c|c|c|c|c|c|c|c|c|}
\hline \multirow[b]{2}{*}{ Insult } & \multirow[b]{2}{*}{ Outcome } & \multirow[b]{2}{*}{ Age $(y r)$} & \multirow[b]{2}{*}{ ISS } & \multicolumn{2}{|c|}{ Time (h) from: } & \multicolumn{4}{|c|}{ BAL } & \multirow{2}{*}{$\begin{array}{c}\text { Blood } \\
\begin{array}{c}\text { Inter- } \\
\text { leukin-8 } \\
(\mathrm{ng} / \mathrm{mL})\end{array}\end{array}$} \\
\hline & & & & $\begin{array}{c}\text { Symptoms } \\
\text { to } \\
\text { sampling }\end{array}$ & $\begin{array}{l}\text { Sampling } \\
\text { to ARDS } \\
\text { diagnosis }\end{array}$ & $\begin{array}{c}\text { Total } \\
\text { cell } \\
\text { count } \\
\left(10^{9} / \mathrm{L}\right)\end{array}$ & $\begin{array}{c}\% \\
\text { PMN }\end{array}$ & $\begin{array}{c}\text { Total } \\
\text { PMN } \\
\text { count } \\
\left(10^{9} / \mathrm{L}\right)\end{array}$ & $\begin{array}{c}\text { Inter- } \\
\text { leukin-8 } \\
(\mathrm{ng} / \mathrm{mL})\end{array}$ & \\
\hline \multicolumn{11}{|l|}{ ARDS patients } \\
\hline 1 trauma & Alive & 18 & 29 & $2 \cdot 5$ & 6 & 7 & $4 \cdot 0$ & $0 \cdot 28$ & 0.229 & $16 \cdot 8$ \\
\hline 2 trauma & Died & 53 & 43 & 1.5 & 48 & 25 & $12 \cdot 0$ & 3.00 & 0.051 & $3 \cdot 10$ \\
\hline 4 trauma & Alive & 32 & 27 & $2 \cdot 2$ & 72 & 28 & 2.0 & 0.56 & $18 \cdot 9$ & 0.476 \\
\hline 5 perforated bowel & Died & 77 & $\ldots$ & 72 & 24 & 11 & $12 \cdot 0$ & $1 \cdot 32$ & 0.738 & 0.392 \\
\hline 6 perforated bowel & Alive & 75 & . & 23 & 12 & 16 & $3 \cdot 0$ & 0.48 & $0 \cdot 786$ & $8 \cdot 70$ \\
\hline 7 pancreatitis & Died & 71 & . & 24 & 24 & 9 & $1 \cdot 0$ & 0.09 & $0 \cdot 246$ & $13 \cdot 7$ \\
\hline Mean $(S E)$ & $\ldots$ & $52(9)$ & $36(5)$ & $19 \cdot 9(10 \cdot 1)$ & $37(10)$ & $16(3)$ & $5.0(1.9)$ & $0.84(0.39)$ & $3.06(2.64)$ & $6 \cdot 23(2 \cdot 60)$ \\
\hline \multicolumn{11}{|l|}{ Non-ARDS patients } \\
\hline 8 trauma & Alive & 20 & 27 & $1 \cdot 1$ & . & 10 & $2 \cdot 5$ & $0 \cdot 25$ & 0.074 & 0.360 \\
\hline 9 trauma & Died & 55 & 29 & $1 \cdot 8$ & . & 14 & $6 \cdot 0$ & $0 \cdot 81$ & 0 & $0 \cdot 863$ \\
\hline 10 trauma & Died & 23 & 25 & 0.7 & . & 15 & 1.5 & $0 \cdot 23$ & 0.031 & $1 \cdot 80$ \\
\hline 12 trauma & Alive & 18 & 29 & $2 \cdot 8$ & .. & 11 & $7 \cdot 0$ & 0.77 & $0 \cdot 112$ & 0.779 \\
\hline 13 trauma & Alive & 18 & 38 & $0 \cdot 8$ & $\ldots$ & 9 & $4 \cdot 0$ & 0.36 & 0.008 & 0.092 \\
\hline 14 trauma & Alive & 50 & 50 & $3 \cdot 0$ & . & 14 & 0.5 & 0.07 & 0.003 & $1 \cdot 70$ \\
\hline 15 trauma & Died & 26 & 43 & $3 \cdot 3$ & . & 12 & $5 \cdot 0$ & 0.60 & 0.005 & $1 \cdot 40$ \\
\hline 16 trauma & Alive & 21 & 19 & 1.9 & .. & 12 & $1 \cdot 0$ & 0.12 & 0 & $21 \cdot 0$ \\
\hline 17 trauma & Alive & 33 & 27 & $2 \cdot 5$ & . & 6 & $8 \cdot 0$ & 0.48 & 0 & 0.826 \\
\hline 18 trauma & Alive & 25 & 16 & $2 \cdot 1$ & . & 28 & $2 \cdot 0$ & 0.56 & $0 \cdot 141$ & $2 \cdot 70$ \\
\hline 19 trauma & Alive & 84 & 29 & 0.9 & . & 16 & $3 \cdot 0$ & 0.48 & $0 \cdot 102$ & $0 \cdot 204$ \\
\hline 20 pancreatitis & Alive & 60 & $\ldots$ & 36 & $\ldots$ & 6 & 3.0 & $0 \cdot 18$ & 0.046 & $0 \cdot 183$ \\
\hline 21 pancreatitis & Alive & 81 & $\ldots$ & 12 & .. & 8 & $8 \cdot 0$ & 0.64 & 0.064 & 1.80 \\
\hline 22 pancreatitis & Alive & 51 & $\ldots$ & 12 & .. & 12 & $4 \cdot 0$ & 0.48 & 0 & 25.0 \\
\hline 23 pancreatitis & Alive & 58 & . & 24 & . & 27 & 0.5 & $0 \cdot 14$ & 0.083 & $7 \cdot 00$ \\
\hline 24 pancreatitis & Alive & 64 & . & 72 & $\ldots$ & 14 & $3 \cdot 0$ & 0.42 & 0.054 & 0 \\
\hline 25 pancreatitis & Alive & 53 & . & 60 & . & 10 & $2 \cdot 0$ & 0.20 & $0 \cdot 120$ & $2 \cdot 50$ \\
\hline 26 perforated bowel & Alive & 41 & . & 48 & $\ldots$ & 14 & $4 \cdot 0$ & 0.56 & 0.042 & $2 \cdot 40$ \\
\hline 27 perforated bowel & Alive & 51 & . & 6 & $\ldots$ & 10 & $0-5$ & 0.05 & $0 \cdot 147$ & 0.455 \\
\hline 28 perforated bowel & Alive & 61 & . & 24 & . & 18 & $2 \cdot 0$ & 0.36 & 0.066 & 41.2 \\
\hline 29 perforated bowel & Died & 70 & & 12 & . & 6 & $4 \cdot 0$ & $0 \cdot 24$ & 0.073 & 0.392 \\
\hline
\end{tabular}




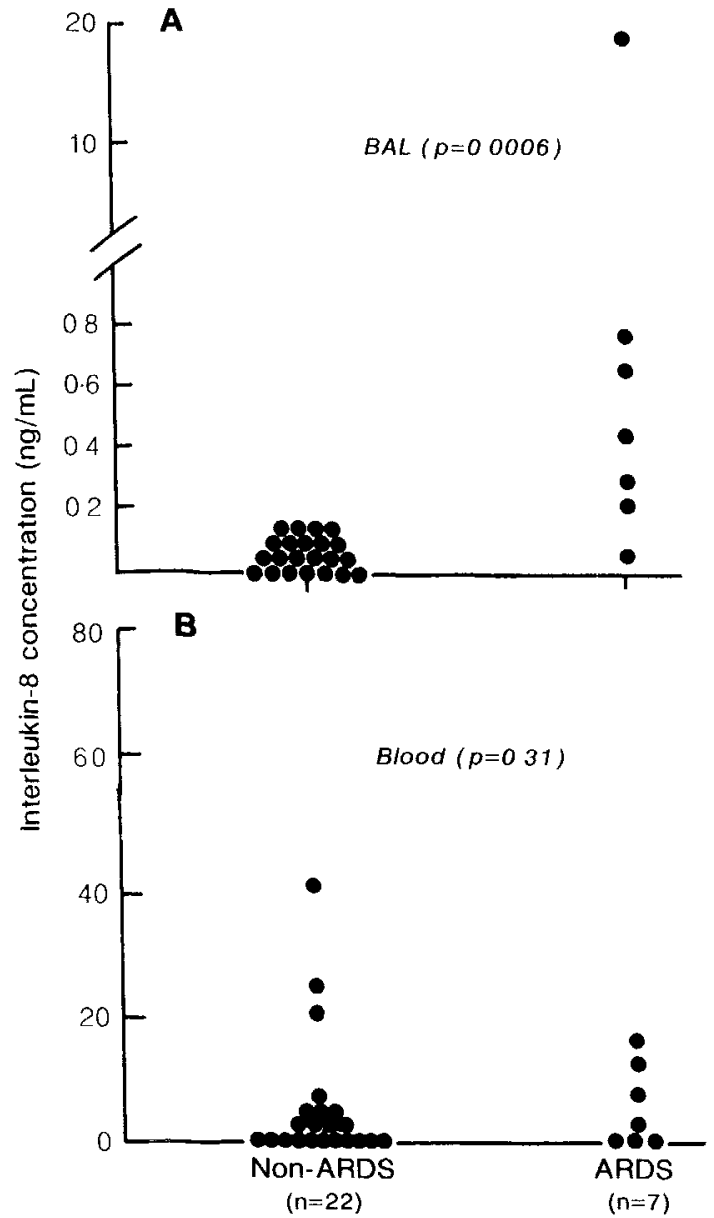

Fig 1-Interleukin-8 concentrations in BAL and blood.

oxygen tension to inspired oxygen concentration, and positive end expiratory pressure (PEEP) used. The lung injury score was derived by dividing the total score by the number of criteria used.

In non-intubated patients a fibreoptic bronchoscope was introduced through the nose after topical lignocaine anaesthesia of the nasal passages and upper airway. In intubated patients, topical lignocaine was not used and the bronchoscope was passed through an indwelling endotracheal tube. The bronchoscope was wedged in either the right middle lobe or the left lingular segment. Three $60 \mathrm{ml}$ volumes of saline $(0.9 \%$ sodium chloride solution) were instilled then gently aspirated immediately. On average $60 \%$ of instilled fluid was recovered (range 40-85\%). All bronchoscopy procedures were done by one doctor (S. C. D.). Recovered fluid was stored at $4^{\circ} \mathrm{C}$ until processing within $1 \mathrm{~h}$. After straining through sterile gauze to remove mucus, the fluid was centrifuged at $400 \mathrm{~g}$ at $4^{\circ} \mathrm{C}$ for $10 \mathrm{~min}$ to recover cells. Total cell counts were done with a haemocytometer. Samples of cells were pelleted onto glass slides with a Cytospin 2 (Shandon Scientific, Cheshire, UK) and stained with Diff-Quick (Merz-Dade AG, Dudingen, Switzerland), a modified Wright-Giemsa stain. Differential counts were made by counting 500 cells under oil immersion $(\times 100)$. The BAL supernatant was respun at $1000 \mathrm{~g}$ for $10 \mathrm{~min}$ at $4^{\circ} \mathrm{C}$ to remove cellular debris and stored at $70^{\circ} \mathrm{C}$ until assay for interleukin-8.

BAL cell cytospins were stained for intracellular interleukin -8 by standard indirect immunohistochemical methods. An alkalinephosphatase-linked rabbit antibody to goat immunoglobulin was used as second antibody. Confocal images of fluorescent staining were obtained with a Zeiss LSM microscope (Oberkochen, Germany).

At the time of venous sampling for clinical indications, $5 \mathrm{ml}$ blood was taken for study purposes. For trauma patients, this sample was taken on initial presentation; for other patient groups it was taken on day 1 of hospital admission. All blood samples were stored at $4^{\circ} \mathrm{C}$ until time of processing, which was within $1 \mathrm{~h}$ of collection. Blood samples were centrifuged at $1000 \mathrm{~g}$ for $10 \mathrm{~min}$ at $4^{\circ} \mathrm{C}$. Plasma was aspirated and stored at $-70^{\circ} \mathrm{C}$.

Extracellular immunoreactive interleukin-8 was quantified by a modification of a double-ligand enzyme-linked immunosorbent assay (ELISA). ${ }^{19}$ Rabbit antibody to interleukin-8 was bound to
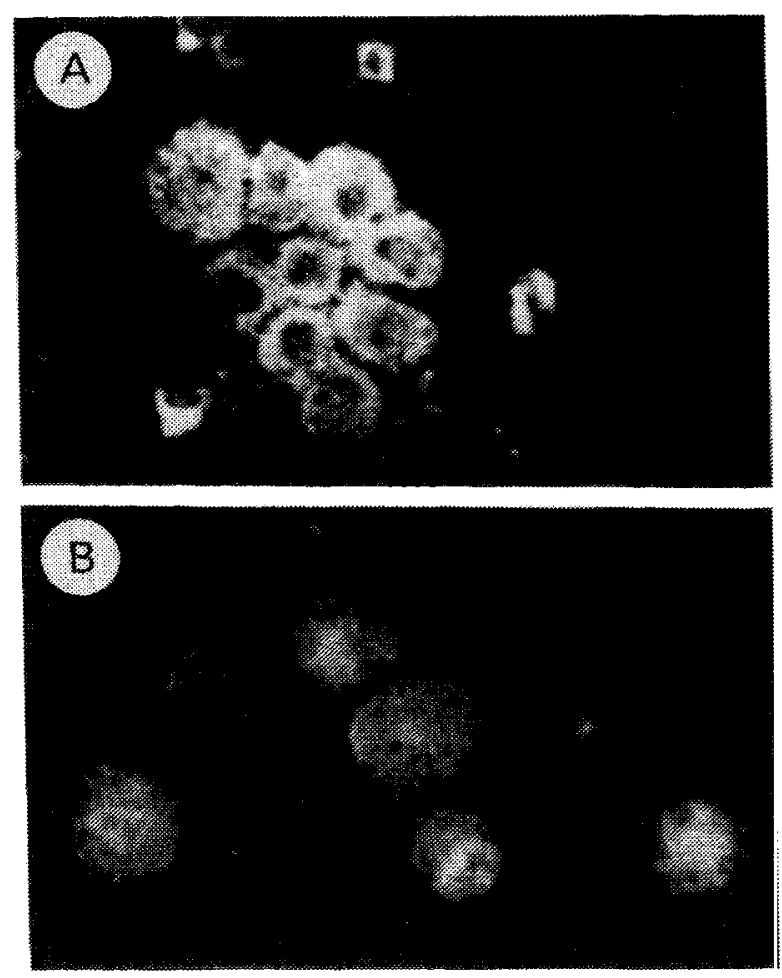

Fig 2-Immunohistochemical analysis and fluorescent staining for interleukin-8 within alveolar macrophages from BAL samples on initial hospital presentation.

$A=$ patient 1 , who progressed to ARDS. $B=$ patient 17 , no ARDS, $\times 1600$

microtitre plates (Nunc Immuno-Plate I 96-F; Naperville, Illinois, USA) by incubation ( $50 \mu \mathrm{l}$ per well of $1 \mathrm{ng} / \mathrm{mL}$ antibody in 0.6 $\mathrm{mmol} / \mathrm{L}$ sodium chloride, $0.26 \mathrm{~mol} / \mathrm{L}$ boric acid, and $0.08 \mathrm{~mol} / \mathrm{L}$ sodium hydroxide $\mathrm{pH} 9 \cdot 6$ ) for $16 \mathrm{~h}$ at $4^{\circ} \mathrm{C}$. After this, and each other step, the plates were washed four times with phosphate-buffered saline ( $\mathrm{pH} 7.5$ ) containing $0.05 \%$ Tween 20 . Non-specific binding sites were blocked by incubation with $2 \%$ bovine serum albumin in phosphate-buffered saline. Samples ( $50 \mu \mathrm{l}$ per well undiluted, $1 / 5$, and $1 / 10$ dilutions of cell-free supernatant) were incubated in the wells for $1 \mathrm{~h}$ at $37^{\circ} \mathrm{C}$, then labelled free antibody (biotinylated rabbit antibody to interleukin- $-8,3.5 \mathrm{ng} / \mathrm{mL}$ ) was added and after $30 \mathrm{~min}$ incubation, streptavidin-peroxidase conjugate (Bio-Rad Laboratories, Richmond, California, USA) was added for a further incubation of $30 \mathrm{~min}$ at $37^{\circ} \mathrm{C}$. Chromogen substrate (Bio-Rad) was added and the plates were incubated at room temperature to the desired extinction. The reaction was terminated with $50 \mu \mathrm{L}$ per well of $3 \mathrm{~mol} / \mathrm{L}$ sulphuric acid. Plates were read at $490 \mathrm{~nm}$ in an ELISA reader. Standards were $1 / 2 \log$ dilutions of recombinant interleukin-8, from $1 \mathrm{pg} / \mathrm{mL}$ to $100 \mathrm{ng} / \mathrm{mL}$. This method consistently detected interleukin-8 concentrations above $10 \mathrm{pg} / \mathrm{mL}$.

Comparisons of patient groups were made by non-parametric methods-the Mann-Whitney test or Spearman rank correlation coefficient, where appropriate. Significance was defined as $p<0.05$.

\section{Results}

Samples obtained from the 16 multiple trauma patients were taken on average $2 \cdot 0$ (range $0 \cdot 7-3 \cdot 3$ ) $\mathrm{h}$ after the trauma episode. The range of injury severity scores for this group of patients was $16-54$. No significant correlation was found between the initial interleukin-8 concentration found in blood and BAL samples and injury severity score $(p=0.35$ and $\mathrm{p}=0.94$ ).

Among the pancreatitis patients, 4 had gallstone-related disease and 3 alcohol-related disease. The duration of symptoms before sampling was 34.3 (range 12-72) h for pancreatitis patients and 33.0 (range $6-72$ ) h for patients with perforated bowel. Of the 29 patients enrolled, 7 subsequently developed ARDS. 10 of the 29 patients enrolled were smokers; 3 of the 7 who progressed to ARDS 
and 7 of 22 who did not. 3 of the 7 patients with ARDS died compared with 5 of the 22 patients without ARDS. Clinical details are given in the table.

The mean BAL concentration of interleukin- 8 was significantly higher for the ARDS group than for the non-ARDS group (table, fig 1). No significant relation to ARDS development was found for blood interleukin-8 measurements (table, fig 1). Immunocytochemical tests for interleukin-8 showed significantly greater staining of alveolar macrophages from patients who subsequently progressed to ARDS than of macrophages from non-ARDS patients (fig 2).

\section{Discussion}

Our findings suggest that BAL concentrations of interleukin-8 may have prognostic value for the development of ARDS in at-risk patients. In view of the complex nature of the inflammatory process in patients with multiple trauma and other disorders predisposing to ARDS, it is not surprising that the search for an early common predictive marker from blood samples has been unsuccessful. ${ }^{10,14,15}$ Most previous studies have enrolled patients after admission to intensive care units, when the cellular process of ARDS has been under way for some time. This study was designed to seek evidence for early predictive inflammatory events in blood and in the target organ, the lungs, by studying BAL samples from at-risk patients enrolled at hospital presentation.

Excessive inflammatory-cell activation, especially neutrophil activation, has been implicated in ARDS.$^{3,6-8} \mathrm{At}$ some stage during the evolution of lung injury, local chemoattractants must be generated to drive neutrophil recruitment. Interleukin-8 is a potent and specific neutrophil chemotactic factor, ${ }^{20}$ which also induces transendothelial migration, rises in cytoplasmic calcium, release of reactive oxygen metabolites, and neutrophil degranulation. ${ }^{21-23}$ The potential importance of interleukin8 in the pathogenesis of inflammatory disease has been suggested by findings of increased synthesis by mononuclear cells in rheumatoid joints ${ }^{24}$ and in idiopathic pulmonary fibrosis. ${ }^{25}$ Miller et al $^{9}$ have suggested that interleukin-8 has an important role in ARDS disease pathogenesis. We detected high concentrations of interleukin-8 in BAL from trauma patients, some within $1 \mathrm{~h}$ of injury. Patients who progressed to ARDS had much higher BAL interleukin-8 concentrations than patients who did not develop ARDS. 6 of the 7 patients who progressed to ARDS had initial BAL interleukin-8 concentrations above $0.200 \mathrm{ng} / \mathrm{mL}$; the 22 non-ARDS patients all had values below $0 \cdot 150 \mathrm{ng} / \mathrm{mL}$. Interleukin-8 concentrations in initial blood samples did not predict ARDS development.

Previous reports of BAL in healthy non-smokers describe a percentage yield of neutrophils of between 0 and $12 \%{ }^{26}$ The average yield of neutrophils from our early lung lavages of patients who subsequently progressed to ARDS was only $5 \%$. This finding suggests that our BAL samples were obtained at a very early stage of ARDS pathogenesis, when interleukin- 8 has increased but before substantial numbers of neutrophils have migrated into the airspaces.

The cellular source of the interleukin-8 in BAL is uncertain. Interleukin- 8 was first isolated from the culture supernatants of lipopolysaccharide-stimulated monocytes in vitro. ${ }^{12}$ Other cell types subsequently identified as being able to secrete this cytokine include endothelial cells, neutrophils, lymphocytes, and epithelial cells. ${ }^{19,27-29}$ Although there are several possible sources, other studies show that lung macrophages have the potential to produce large amounts of interleukin-8.

By immunohistochemistry we have obtained preliminary evidence of more interleukin-8 within alveolar macrophages from patients who progressed to ARDS than in alveolar macrophages from patients who did not (fig 2).

On the present criteria, the diagnosis of ARDS is not usually made before the patient reaches the intensive care unit, often days after the provoking insult. Our findings suggest that measurement of interleukin-8 in BAL of at-risk patients could enable early identification of those likely to progress to ARDS. Future therapeutic interventions could then be aimed specifically at a subgroup of very-high-risk patients. Our findings further implicate neutrophils in most cases of ARDS and emphasise the local generation of interleukin-8 and its subsequent effects as possible therapeutic targets for attempts to attenuate or abort the ARDS process before it progresses to full-blown lung injury.

This work was supported by the British Lung Foundation, Chest, Heart and Stroke Association (Scotland), and Scottish Hospital Endowments Research Trust.

We thank Ms Marie Burdick (University of Michigan) and Dr Sarah Howie and Ms Elizabeth Ramage (University of of Edinburgh) for technical expertise; Dr Robert Elton for statistical advice; and the staff of the Bronchoscopy Suite, Department of Medicine, Intensive Therapy Unit, Accident and Emergency Department, and Department of Surgery, Royal Infirmary, and the Intensive Therapy Unit, Western General Hospital, Edinburgh.

\section{REFERENCES}

1. McNaughton PD, Evans TW. Management of adult respiratory distress syndrome. Lancet 1992; 339: 469-72.

2. Petty TL, Fowler AA. The adult respiratory distress syndrome. In Flenley DC, Petty TL, eds. Recent advances in respiratory medicine. Edinburgh: Churchill Livingstone, 1983: 103-14.

3. Repine JE, Beehler CJ. Neutrophils and adult respiratory distress syndrome: two interlocking perspectives in 1991. Am Rev Respir Dis $1991 ; 144: 251-52$.

4. Rinaldo JE, Rogers RM. Adult respiratory distress syndrome: changing concepts of lung injury and repair. $N$ Engl f Med 1982; 306: 900-10.

5. Warshawski FJ, Sibbald WJ, Driedger AA, Cheung H. Abnormal neutrophil-pulmonary interaction in the adult respiratory distress syndrome. Am Rev Respir Dis 1986; 133: 797-804.

6. Weiland JE, Davis WB, Holter JF, Mohammed JR, Dorinsky PM, Gadek JE. Lung neutrophils in the adult respiratory distress syndrome: clinical and pathophysiological significance. Am Rev Respir Dis 1986; 133: $218-25$

7. Rocker GM, Wiseman MS, Pearson D, Shale DJ. Diagnostic criteria for adult respiratory distress syndrome: time for reappraisal. Lancet 1989 ; i: $120-23$.

8. Christner P, Fein A, Goldberg S, et al. Collagenase in the lower respiratory tract of patients with the adult respiratory distress syndrome. Am Rev Respir Dis 1985; 131: 690-95.

9. Miller EJ, Cohen AB, Nagao S, et al. Elevated levels of NAP-1/ interleukin-8 are present in the airspaces of patients with the adult respiratory distress syndrome and are associated with increased mortality. Am Rev Respir Dis 1992; 146: 427-32.

10. Rinaldo JE, Christman MD. Mechanisms and mediators of the adult respiratory distress syndrome. Clin Chest Med 1990; 11: 621-32.

11. Larsen GL, Henson PM. Mediators of inflammation. Annu Rev Immunol $1983 ; 1: 335-54$.

12. Kunkel SL, Standiford T, Kasahara K, Strieter RM. Interleukin-8: the major neutrophil chemotactic factor in the lung. Exp Lung Res 1991; 17: $17-23$.

13. Standiford TJ, Kunkel SL, Rolfe MW, Evanoff HL, Allen RM, Strieter RM. Regulation of human alveolar macrophage and blood monocytederived interleukin- 8 by prostaglandin $\mathrm{E}_{2}$ and dexamethasone. $A m \mathcal{F}$ Respir Cell Mol Biol 1992; 6: 675-81.

14. Parsons PE, Worthen GS, Moore EE, Tate RM, Henson PM. The association of circulating endotoxin with the development of the adult respiratory distress syndrome. Am Rev Respir Dis 1989; 140: 294-301.

15. Parsons PE, Moore FA, Moore EE, Ikle DN, Henson PM, Worthen GS. Studies on the role of tumour necrosis factor in adult respiratory distress syndrome. Am Rev Respir Dis 1992; 146: 694-700. 
16. Osborne DH, Imrie CW, Carter DC. Biliary surgery in the same admission for acute pancreatitis. Br f Surg 1981; 68: 758-61.

17. Boyd CR, Tolson MA, Copes WS. Evaluating trauma care: the TRISS method. $f$ Trauma 1987; 27: 370-78.

18. Murray JF, Matthay MA, Luce JM, Flick MR. An expanded definition of the adult respiratory distress syndrome. Am Rev Respir Dis 1988; 138: 720-23.

19. Standiford TJ, Kunkel SL, Basha MA, et al. Interleukin-8 gene expression by a pulmonary epithelial cell line: a model for cytokine networks in the lung. $f$ Clin Invest 1990; 86: 1945-53.

20. Schroder JM, Christophers E. Secretion of novel and homologous neutrophil-activating peptides by LPS-stimulated human endothelial cells. F Immunol 1989; 142: 244-51.

21. Huber AR, Kunkel SL, Todd RF, Weiss SJ. Regulation of transendothelial neutrophil migration by endogenous interleukin-8. Science 1991; 254: 99-102.

22. Peveri $P$, Walz A, Dewald B, Baggiolini M. A neutrophil-activating factor produced by human mononuclear phagocytes. F Exp Med 1988; 167: 1547-59.

23. Willems J, Joniau S, Cinque S, Van Damme J. Human granulocyte chemotactic peptide (IL-8) as a specific neutrophil degranulator: comparison with other monokines. Immunology 1989; 67: 540-42.

24. Koch AE, Kunkel SL, Burrows JC, et al. Synovial tissue macrophages as a source of the chemotactic cytokine IL-8. F Immunol 1991; 147: 2187-95.

25. Lynch JP, Standiford TJ, Rolfe MW, Kunkel SL, Strieter RM. Neutrophilic alveolitis in idiopathic pulmonary fibrosis. Am Rev Respir Dis 1992; 145: 1433-39.

26. The BAL Cooperative Steering Committee. Bronchoalveolar lavage constituents in healthy individuals, idiopathic pulmonary fibrosis, and selected comparison groups. Am Rev Respir Dis 1990; 141: S169-205.

27. Strieter RM, Kunkel HJ, Showell HJ, et al. Endothelial cell gene expression of a neutrophil chemotactic factor by TNF, IL1b or LPS. Science 1989; 243: 1467-69.

28. Strieter RM, Kasahara K, Allen R, Showell HJ, Standiford TJ, Kunkel SL. Human neutrophils exhibit disparate chemotactic factor gene expression. Biochem Biophys Res Commun 1990; 173: 725-30.

29. Gregory H, Young J, Schroder JM, Mrowietz U, Christophers E. Structure determination of a human lymphocyte derived neutrophil activating peptide (LYNAP). Biochem Biophys Res Commun 1988; 151: $883-90$.

\title{
Detection of rifampicin-resistance mutations in Mycobacterium tuberculosis
}

\author{
AMALIO TELENTI PAUL IMBODEN FRANCINE MARCHESI \\ DOUglas LOWRIE STEWART COLE M. JOSEPH COLSTON \\ LUKAS MATTER KURT SCHOPFER THOMAS BODMER
}

Control of tuberculosis is threatened by widespread emergence of drug resistance in Mycobacterium tuberculosis. Understanding the molecular basis of resistance might lead to development of novel rapid methods for diagnosing drug resistance. We set out to determine the molecular basis of resistance to rifampicin, a major component of multidrug regimens used for treating tuberculosis.

Resistance to rifampicin involves alterations of RNA polymerase. The gene that encodes the RNA polymerase subunit $\beta$ (rpoB) was cloned. Sequence information from this gene was used to design primers for direct amplification and sequencing of a $411 \mathrm{bp}$ rpoB fragment from 122 isolates of $M$ tuberculosis. Mutations involving 8 consenved aminoacids were identified in 64 of 66 rifampicinresistant isolates of diverse geographical origin, but in none of 56 sensitive isolates. All mutations were clustered within a region of 23 aminoacids. Thus, substitution of a limited number of highly conserved aminoacids encoded by the $r p o B$ gene appears to be the molecular mechanism responsible for "single step" high-level resistance to rifampicin in $M$ tuberculosis. This information was used to develop a strategy (polymerase chain reactionsingle-strand conformation polymorphism) that allowed efficient detection of all known rifampicinresistant mutants.

These findings provide the basis for rapid detection of rifampicin resistance, a marker of multidrug-resistant tuberculosis.

Lancet $1993 ; 341: 647-50$.

\section{Introduction}

Resistance of Mycobacterium tuberculosis to antituberculous drugs has emerged as a major public-health threat, particularly among patients infected with human immunodeficiency virus. ${ }^{1-5}$ Rifampicin is a key component of therapeutic regimens; therefore, patients in whom resistance to this drug develops have a poor outlook, particularly if rifampicin resistance is associated with resistance to other antituberculous drugs. ${ }^{6-8}$

Development of resistance to rifampicin in $M$ tuberculosis follows a "single-step" high-level resistance pattern." Mutants arise spontaneously in strains not exposed previously to the antibiotic at a rate of one mutation per $10^{-7}$ to $10^{-8}$ organisms. ${ }^{9,10}$ Resistance has been attributed to changes in RNA polymerase, ${ }^{11}$ but the precise molecular mechanism has not been established in mycobacteria. The structural and functional organisation of RNA polymerases is conserved among bacteria. ${ }^{12}$ In Escherichia coli resistance to rifampicin is associated with specific nucleicacid substitutions in the gene encoding for RNA polymerase subunit $\beta$ (rpoB). ${ }^{13}$ To evaluate the moleclar mechanism of resistance to rifampicin in $M$ tuberculosis, we identified, cloned, and partly sequenced the $r p o B$ of this organism, and compared this sequence with those of polymerase chain reaction (PCR) generated fragments of the $r p o B$ from 122 clinical isolates of rifampicin resistant and sensitive $M$ tuberculosis. We have used this information to develop a novel strategy for rapid detection of rifampicin resistance.

ADDRESSES: Institute for Medical Microbiology, University of Berne, Friedbuehlstrasse 51, 3010 Berne, Switzerland (A. Telenti, MD, P. Imboden, PhD, F. Marchesi, L. Matter, MD, K. Schopfer, MD, T. Bodmer, MD); National Institute for Medical Research, London. UK (D. Lowrie, PhD, M. J. Colston, PhD); and Laboratory of Bacterial Molecular Genetics, Pasteur Institute, Paris, France (S. Cole, PhD). Correspondence to Dr A. Telenti. 